\title{
COMPRESSIVE STRENGTH CLASSIFICATION OF LIGHTWEIGHT AGGREGATE CONCRETE USING A SUPPORT VECTOR MACHINE MODEL
}

\author{
ANTONIO JOSÉ TENZA-ABRIL ${ }^{1}$, ROSANA SATORRE-CUERDA ${ }^{2}$, PATRICIA COMPAÑ-ROSIQUE ${ }^{2}$, \\ FRANCISCO JOSÉ NAVARRO-GONZÁLEZ ${ }^{3} \&$ YOLANDA VILLACAMPA $^{3}$ \\ ${ }^{1}$ Department of Civil Engineering, University of Alicante, Spain \\ ${ }^{2}$ Department of Computer Science and Artificial Intelligence, University of Alicante, Spain \\ ${ }^{3}$ Department of Applied Mathematics, University of Alicante, Spain
}

\begin{abstract}
Lightweight aggregates (LWA) are used to produce low-density concretes required for building applications. Lightweight aggregate concrete (LWAC) is a multi-purpose material for construction, which offers technical, economical and environment benefits, and it is produced by replacing the normal-weight aggregates with LWA, depending upon the requirements of density and strength. LWAC is a complex composite material, and a model of its compressive strength must be highly nonlinear because it is very sensitive to its ingredients, so modelling its behaviour is a difficult task. Many studies have tried to develop accurate and effective predictive models for LWAC compressive strength. In this study, a support vector machine (SVM) learning algorithm is used to propose a model to classify the compressive strength of a wide range of LWAC. A dataset of 241 different LWACs were used for classifying the compressive strength into six different classes (from low-strength to high-strength) using different variables - quantity of cement, water and LWA in the dosage and density of the LWAC produced. The results show that increasing the variables means the model becomes more accurate up to approximately an $80 \%$ rate of success. The SVM model proved to be a significant tool to classify the compressive strength of LWAC contributing to engineers avoiding costly experimental trial tests.

Keywords: lightweight concrete, aggregate, vibration, classification, modelling.
\end{abstract}

\section{INTRODUCTION}

Due to the increasing energy consumption, the requirements for higher building energy efficiency have been widely considered [1], [2]. Insulation materials, such as, cement-based porous materials, including aerated concrete, foamed concrete and lightweight aggregate concrete (LWAC), exhibit superior fire resistance and more desirable insulation properties than the conventional concrete materials [3], [4].

LWAC is an important and versatile material for use in modern construction [5]. The application of lightweight concrete is not only used as an insulation material, it has other actual engineering applications such as large-span bridges, high-rise buildings, tall concrete wind towers [6] and offshore oil platforms because of the lower density, higher strength/weight ratio and better durability properties [7].

Research has been conducted worldwide on a large number of natural and artificial lightweight aggregates used in the manufacture of mortar and concrete. The absorption caused by the lightweight aggregate is mainly responsible for the difficulty during the production of lightweight aggregate concrete (LWAC) in practical situations [8]. LWA are generally porous materials, which tend to absorb water in aqueous [9] and viscous medium [10]. The mix design of LWAC is more complex than a conventional normal-weight concrete because there are more design parameters - such as absorbed water during the mixing of concrete and proportioning of different aggregate sizes. Changing the LWA used in the concrete varies other properties of LWAC like compressive strength and density which is not predictable for all types of lightweight aggregates. For this reason, many different techniques 
have been used to provide better mixtures design using different types of approaches [11], such as genetic algorithms [5], artificial neural networks [12], [13] or finite elements [14].

There are also difficulties in the placement of the LWAC. During the mixing of LWAC, due to the different densities of its components, LWAC is susceptible to segregation of the aggregates [15]. In fact, during the vibration of the concrete, lightweight aggregates tend to float. Segregated concretes are susceptible to an increased risk of cracking due to the separation of the aggregates from the rest of the mixture reducing their durability [13]. There are several methods to measure the segregation [16], which can be detected by ultrasonic pulse velocity [13] and can be measured through image analysis [17] because the manufacture process can affect it [18]. There are numerical models for describing it [15] and also neural networks have been applied to analyse the phenomenon [13]. The supplementary materials can also affect the segregation [19].

The most important required property of LWC is its compressive strength and its density. The compressive strength of LWC has great influence on its structural performance and is significantly affected by the composition - materials, the dosage of chemical and mineral admixtures, types of aggregate used, packing density and water to binder ratio (W/B) [20].

Support-vector machines (SVMs) are a supervised learning model with associated learning algorithms developed by Cortes and Vapnik [21] used for classification and regression analysis. The technique appeared from the theory of statistical learning postulated by Vapnik and Chervonenkis [22], [23]. SVMs were introduced in 1992 and became popular when they obtained better results than neural networks in handwriting recognition using pixels as input data [21]. The technique transforms the input space into another space of higher dimension, in which the problem can be solved by means of an optimal hyperplane (of maximum margin). It performs extremely complex data transformations and then finds out how to separate the data according to the labels or defined outputs (Fig. 1). The technique has been used to solve different problems in engineering [24]-[26], used in normal-weight concrete [27], [28] as well as in LWAC [29].

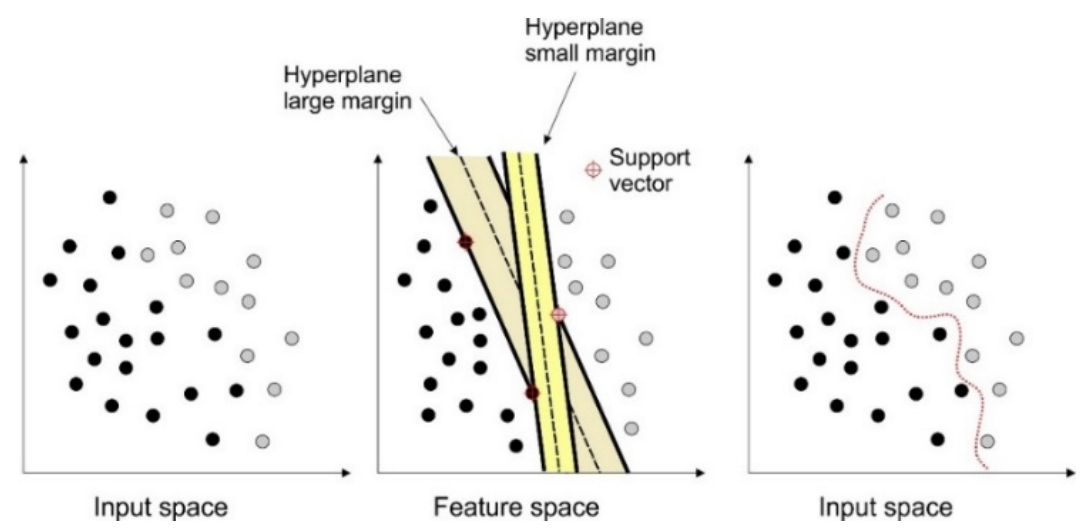

Figure 1: Concept of support vector machine classification. (Source: Figure adapted from Hariri-Ardebili and Pourkamali-Anaraki [24].)

The original proposal using SVM is to classify the points into two categories, but it is also extendable to $\mathrm{n}$ categories. In this study the classification of the compressive strength of LWAC using SVM is investigated, the points were classified into 6 different categories corresponding to compressive strength classification. 
The main objective using SVM is to take as an input a set of points (parameters of the LWAC design from the literature) in which each of them belongs to one of several possible categories (compressive strength category). An algorithm based on SVM builds a model capable of predicting to which category a new point belongs (using Matlab ${ }^{\circledR}$ ).

\section{MATERIALS AND METHODOLOGY}

\subsection{Experimental database}

In this research, 241 groups of test data of LWAC from the literature were collected [30][38]. The concretes studied used different types of LWA: Argex ${ }^{\circledR}$, Arlita Leca ${ }^{\circledR}$, natural pumice stone, Slate $^{\circledR}$, Rthyolite $^{\circledR}$, oil palm shell and recycled LWA.

\subsubsection{Input variables: Mixture proportions}

The goal is to design a classifier from the training data that allows us to predict the classification of compressive strength for a set of materials properties and some quantities for the dosage. The inputs used were:

- LWA dry density: Depending upon the source of material, the dry density of the aggregate from the literature ranges from 573 to $2650 \mathrm{~kg} / \mathrm{m}^{3}$.

- Amount of water: The water used to manufacture the concrete used as data, ranges from 85 to 287 litres per cubic meter. In this study, only the effective water is considered because the water absorption of the LWA varies depending on the aggregate pore structure [39] and the value differs if the test is carried out in water or in the mass of the concrete [10].

- Amount of cement: The LWACs of the study were manufactured with a range of 150 to $640 \mathrm{~kg}$ in one cubic meter.

- Lightweight aggregate: from 0 to $863 \mathrm{~kg}$ per cubic meter (from normal-weight concrete to LWAC).

As seen in Fig. 2, the LWAC compressive strength does not present a linear trend because the LWAC used in this research had a wide range of results and input parameters (Fig. 2).

\subsubsection{Output variable: Compressive strength}

The compressive strength is a key issue but it is a random variable that can vary over the time, even in a single structure [40]. To enhance professional practice an accurate and appropriate classification of compressive concrete strength is required [41]. Literature reveals gaps and overlapping in compressive concrete strength classifications. In this study the classification proposed by Sojobi et al. [41] is used because it avoids gaps, vague classification and it is easily understood by the professionals (Table 1).

As can be observed in Fig. 2, the maximum class achieved for lightweight concrete used in the database is a high-strength $(81.6 \mathrm{MPa})$ and the minimum is the low compressive strength $(0.6 \mathrm{MPa})$.

\subsubsection{Supporting Vector Machine (SVM)}

As explained in the introductory section, a Support Vector Machine (SVM) is a discriminating classifier formally defined by a separation hyperplane. In other words, given the training data label (supervised learning), the algorithm produces an optimal hyperplane that categorizes the new examples. In the case of a two-dimensional space, this hyperplane is a line that divides space into two zones where the samples are located to one side or to the other of the line depending on their class. This is extendable to more dimensions. 
a

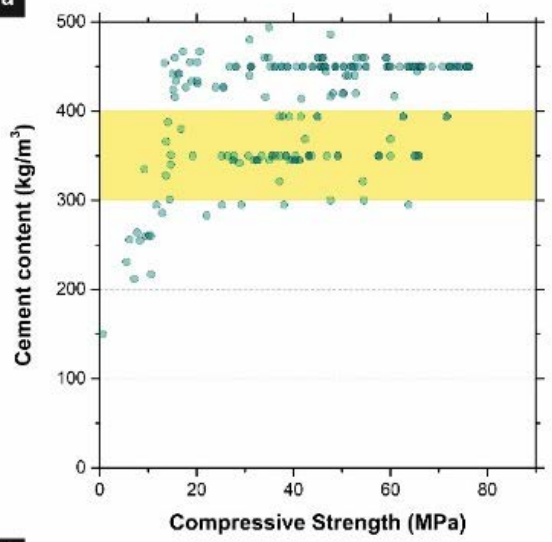

c

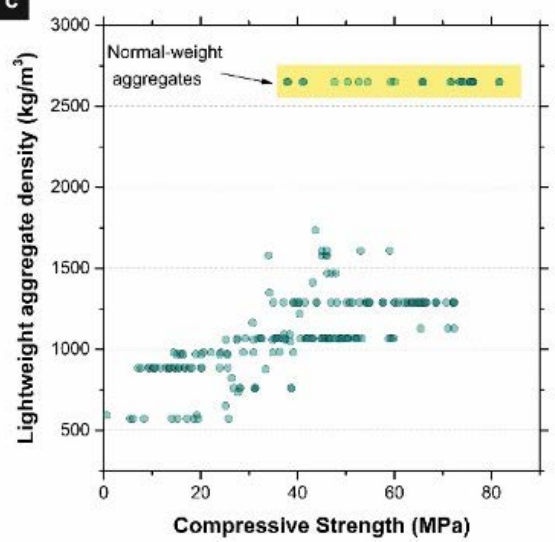

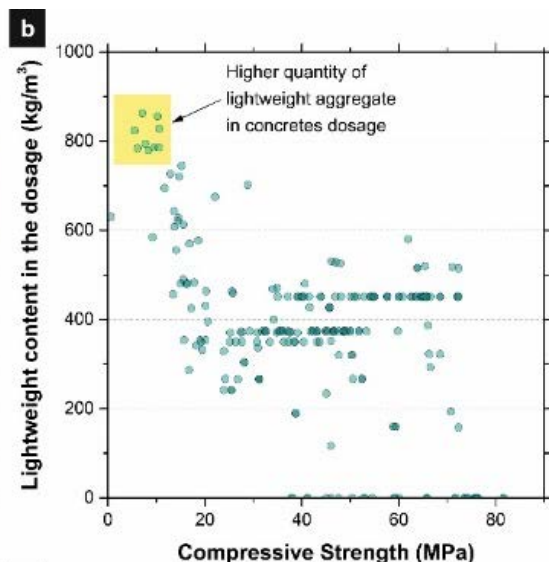

d

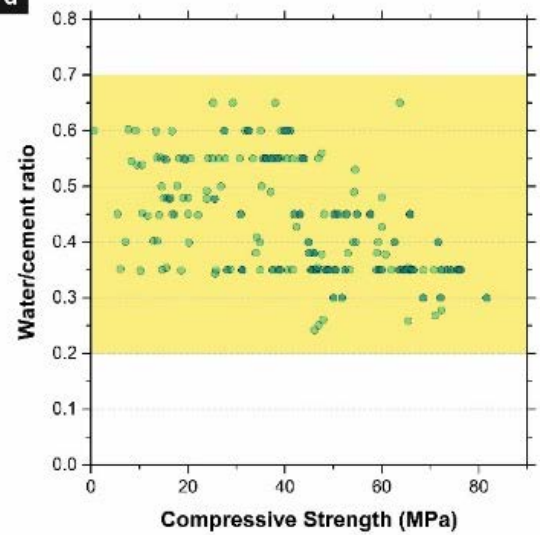

Figure 2: Variation of the properties used for SVM. Compressive strength of the concretes vs (a) Cement content; (b) LWA content; (c) LWA density; (d) W/c ratio.

Table 1: Classification used in the study according to Sojobi et al. [41].

\begin{tabular}{|c|c|c|c|}
\hline \multirow{2}{*}{ Class } & \multicolumn{3}{|c|}{ Classification of concrete according to its compressive strength } \\
\cline { 2 - 4 } & Type of concrete & Subclasses & Compressive strength (MPa) \\
\hline 1 & Low-strength & & $0-19$ \\
\hline 2 & Normal-strength & & $20-39$ \\
\hline 3 & Medium-strength & Low & $40-49$ \\
\hline 4 & & Medium & $50-59$ \\
\hline 5 & & High & $60-69$ \\
\hline 6 & High-strength & Low & $70-84$ \\
\hline 7 & & Medium & $85-99$ \\
\hline 8 & & High & $100-119$ \\
\hline 9 & Ultra-high strength & Low & $120-200$ \\
\hline 10 & & Medium & $200-400$ \\
\hline 11 & & High & $400-600$ \\
\hline 12 & & Very high & $600-1000$ \\
\hline
\end{tabular}


The support vector machine is a generalization of a simple and intuitive classifier called the maximal margin classifier, which was introduced in Section 1. Though it is elegant and simple, this classifier cannot be applied to most data sets, since it requires that the classes be separable by a linear boundary. SVM is intended for the binary classification setting in which there are two classes, it was later extended to handle more than two classes.

To understand the classifier maximal margin, it is necessary to introduce the concept of an optimal separating hyperplane. In a $p$-dimensional space, a hyperplane is a flat affine subspace of dimension $p$ - 1 . It is simple to visualize a hyperplane in two dimensions. However, as the number of dimensions increases, it becomes more difficult to visualize. Fig. 3 shows an example of two-dimensional classification using the online application provided by LIBSVM [42].

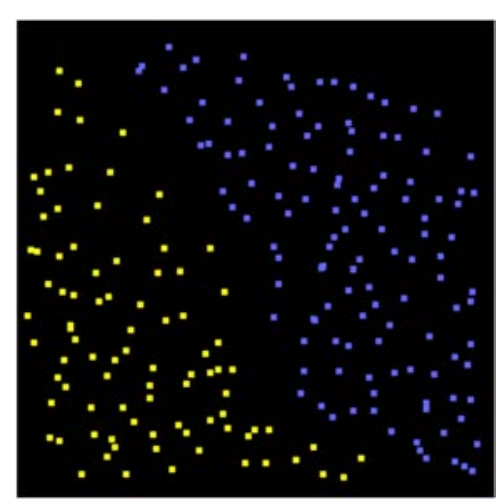

(a)

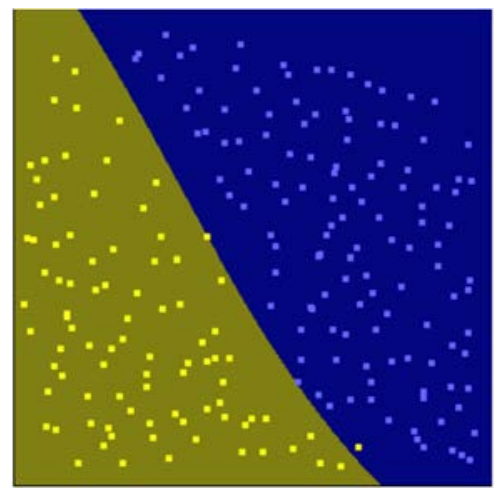

(b)

Figure 3: Two-dimensional classification. (a) Two classes of observations are shown in blue and yellow; (b) An SVM applied to the samples on the left image.

As mentioned above, the support vector classifier is a natural approach for classification in the two-class setting if the boundary between the two classes is linear [43]. The linear support vector classifier can be represented by

$$
f(x)=\beta_{O}+\sum_{i=1}^{n} \alpha_{i}\left\langle x, x_{i}\right\rangle,
$$

where there are $n$ parameters $\alpha_{i}, i=1, \ldots, n$ one per training observation and $\left\langle x, x_{i}\right\rangle$ is the inner product of two r-vectors, in this case, $x$ and $x_{i}$. To estimate the parameters $\alpha_{i}, \ldots, \alpha_{n}$ and $\beta_{\mathrm{O}}$, it is necessary to evaluate the $\left(\begin{array}{l}n \\ 2\end{array}\right)$ inner products $\left\langle x_{i}, x_{i^{\prime}}\right\rangle$ between all pairs of training observations. Thus, to evaluate the function $\mathrm{f}(\mathrm{x})$ it is required to compute the inner product between the new point $\mathrm{x}$ and each of the training points $\mathrm{x}_{\mathrm{i}}$. To summarize, the function is replaced with a generalization of the inner product of the form

$$
K\left(x_{i}, x_{i}\right) \text {, }
$$

where $K$ is some function that we will refer to as a kernel. A kernel is a function that quantifies the similarity of two observations.

Some different types of kernel used in SVM algorithms are:

- The linear kernel. It uses Pearson correlation to quantify the similarity of two pairs of observations (eqn (3)) 


$$
K\left(x_{i}, x_{i \prime}\right)=\sum_{j=1}^{p} x_{i j} \cdot x_{i \prime j} .
$$

- Polynomial kernel. It is possible to replace each instance of eqn (3) with eqn (4), where $\mathrm{d}$ is the polynomial degree and $d>1$. This kernel leads to a more flexible decision boundary. This is equivalent to adapting an SVM in a higher-dimensional space involving polynomials of degree $d$ rather than in the original characteristic space

$$
K\left(x_{i}, x_{i \prime}\right)=\left(1+\sum_{j=1}^{p} x_{i j} \cdot x_{i, j}\right)^{d} .
$$

- Radial kernel. This kernel also matches samples in a higher-dimensional space but it can handle scenarios where the relationship between classes and attributes is not linear. This kernel takes the form given by eqn 5, where $\gamma$ is a positive constant in a space of infinite dimensional characteristics

$$
K\left(x_{i}, x_{i \prime}\right)=\exp \left(-\gamma \cdot \sum_{j=1}^{p}\left(x_{i j}-x_{i, j}\right)^{2}\right) .
$$

\section{RESULTS AND DISCUSSION}

The prediction system is based on a standard C-parameterized margin, C-SVC [21] with Radial kernel [22]. Initially, the features are scaled to (0-1) range before passing them to the SVM, preserving the many values that are already 0 and maintaining matrix scarcity. With the scaled features, a model selection is conducted to boost the performance of the SVM by picking up the best set of parameters. As two parameters have to be selected (C regularization parameter and amplitude), a 2D grid-search is performed, with parameter values varying exponentially in powers of 2 (eqn (6))

$$
C \in\left\{2^{i}: i \in[-7,7] \cap \mathbb{Z}\right\}, \gamma \in\left\{2^{j}: j \in[-7,7] \cap \mathbb{Z}\right\} .
$$

As previously mentioned in Section 2.1, the dataset was composed of 241 elements classified into 6 different types (according to Table 1). There are 12 possible classifications for compressive strength according to Table 1 but the database used for the research had a range of results from 0.6 MPa (Class 1) to $81.6 \mathrm{MPa}$ (Class 6). The independent variables used were the input parameters presented in Section 2.1.1.

For each pair of parameters, a leave-one-out Cross-Validation training gives its accuracy estimation (success percentage in Table 2). Finally, the 2 parameters corresponding to the best accuracy estimation are selected. For the training tests, $85 \%$ (209 samples) of the samples were used, reserving the remaining $15 \%$ for the test ( 32 samples).

Table 2: Success percentage according the number of independent variables.

\begin{tabular}{|l|c|c|c|c|c|c|}
\hline & \multicolumn{5}{|c|}{ Independent variables } \\
\hline & \multicolumn{3}{|c|}{2 variables } & \multicolumn{2}{c|}{3 variables } & All \\
\hline Cement content & $\times$ & $\times$ & & $\times$ & & $\times$ \\
\hline Water content & $\times$ & & $\times$ & $\times$ & $\times$ & $\times$ \\
\hline LWA content & & $\times$ & $\times$ & $\times$ & $\times$ & $\times$ \\
\hline LWA density & & & & & $\times$ & $\times$ \\
\hline Success (\%) & 35.27 & 50.62 & 60.17 & 65.56 & 71.78 & 78.13 \\
\hline
\end{tabular}

The success rate was calculated as the number of successes in the classification by comparing the actual classification and the classification predicted by the model. 
As can be seen in Table 2, when the input variables increase, higher success in the classification model was obtained. This trend is a common behaviour in concrete compressive strength modelling. A better knowledge of the parameters of the concrete dosage allows one to reduce the uncertainty in the prediction and to adjust better to the real result [44]. As can be seen in Table 2, with two independent variables - where the amount of water and cement in the concrete dosage are known (water to cement ratio shown in Fig. 2(d) - the model does not allow obtaining a high success percentage $(35.27 \%)$. This fact is contrary to expectation, because $\mathrm{w} / \mathrm{c}$ is one of the most important factors when dosing a concrete (only very low a/c ratios allow us to obtain concretes with very high resistance [45]). However, when the quantity of water and the quantity of LWA in the manufacture of concrete is known, it is possible to estimate with higher success percentage the LWAC strength class $(60.17 \%)$. With 3 independent variables (Table 2), it is observed again that the quantity of cement in the LWAC dosage is not a decisive factor in the prediction of compressive strength classification. Considering the quantity of cement, the success rate for predicting the compressive strength class is $65.56 \%$ and considering the LWA density is reached the $71.78 \%$ of success. Because of it, in LWAC, the LWA density has more influence in the prediction success than the quantity of cement used in the dosage when a prediction of compressive strength class is required.

The best model had a success of $78.125 \%$, that is, 25 success in the classification of 32 in total used for the test (Fig. 4 shows the prediction vs real classification of the 32 data from the dataset used for the test). As can be seen in Fig. 4, there was a total success in the prediction of LWAC classified as category 1 (low compressive strength) and 6 (ultra-high compressive strength low). The worst classification can be seen in classification 5 (real compressive strength classification) because, as can be seen in Fig. 4, the model classified results as model 2 to 5 . Further research is needed for increasing the success predicting the classification in the middle range of results (class 5) where lower success was observed due to the high variations in the dosage parameters that result in lower accurate prediction.

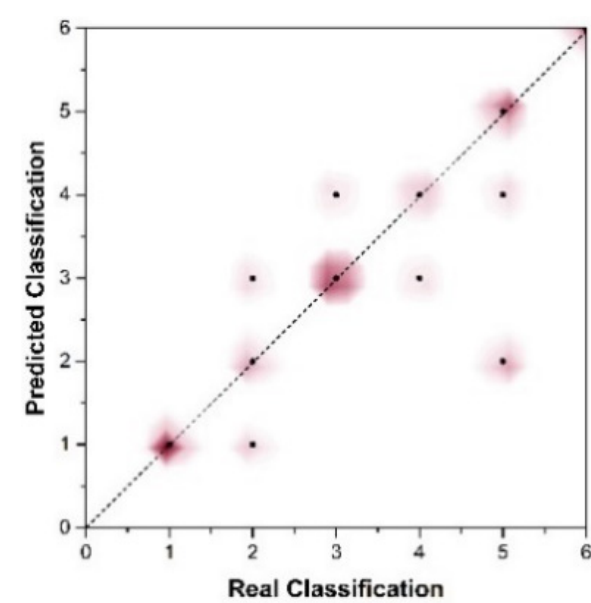

(a)

\begin{tabular}{|c|c|c|c|c|c|c|c|}
\hline & \multicolumn{6}{|c|}{ Real classification } \\
\hline & & 1 & 2 & 3 & 4 & 5 & 6 \\
\hline \multirow{12}{*}{ 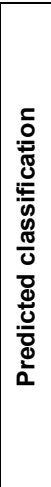 } & \multirow{2}{*}{1} & 5 & 0 & 0 & 0 & 0 & 0 \\
\hline & & $15.6 \%$ & $0.0 \%$ & $0.0 \%$ & $0.0 \%$ & $0.0 \%$ & $0.0 \%$ \\
\hline & \multirow{2}{*}{2} & 1 & 2 & 0 & 0 & 2 & $\overline{0}$ \\
\hline & & $3.1 \%$ & $6.3 \%$ & $0.0 \%$ & $0.0 \%$ & $6.3 \%$ & $0.0 \%$ \\
\hline & \multirow{2}{*}{3} & 0 & 1 & 7 & 1 & 0 & 0 \\
\hline & & $0.0 \%$ & $3.1 \%$ & $21.9 \%$ & $3.1 \%$ & $0.0 \%$ & $0.0 \%$ \\
\hline & \multirow{2}{*}{4} & 0 & 0 & 1 & 2 & 1 & 0 \\
\hline & & $0.0 \%$ & $0.0 \%$ & $3.1 \%$ & $6.3 \%$ & $3.1 \%$ & $0.0 \%$ \\
\hline & \multirow{2}{*}{5} & 0 & 0 & 0 & 0 & 4 & 0 \\
\hline & & $0.0 \%$ & $0.0 \%$ & $0.0 \%$ & $0.0 \%$ & $12.5 \%$ & $0.0 \%$ \\
\hline & \multirow{2}{*}{6} & 0 & 0 & 0 & 0 & 0 & 5 \\
\hline & & $0.0 \%$ & $0.0 \%$ & $0.0 \%$ & $0.0 \%$ & $0.0 \%$ & $15.6 \%$ \\
\hline
\end{tabular}

(b)

Figure 4: Prediction vs real classification of the data. (a) Real and predicted classification; (b) Success number and percentage in the classification using the SVM model with four parameters as input variables and 32 results used for test. Green colour in the diagonal indicates success and red indicates errors. 


\section{CONCLUSIONS}

In this study, a prediction model of LWAC compressive strength was established by SVM. 241 sample data collected from experimental tests were used to develop the SVM model to predict compressive strength. The input variables selected to develop the model were cement, water, LWA content and LWA dry density. The predicted compressive strengths from the developed SVM model matched well and can be potentially used to predict the compressive strength. However, there are ranges of compressive strength where the model does not present accurate results due to the variation of the LWAC properties.

\section{ACKNOWLEDGEMENT}

This research was supported by the University of Alicante (GRE13-03) and (VIGROB-256).

\section{REFERENCES}

[1] Rodriguez-Ubinas, E., Rodriguez, S., Voss, K. \& Todorovic, M.S., Energy efficiency evaluation of zero energy houses. Energy and Buildings, 2014.

[2] Korjenic, A., Petránek, V., Zach, J. \& Hroudová, J., Development and performance evaluation of natural thermal-insulation materials composed of renewable resources. Energy and Buildings, 2011.

[3] Xie, Y., Li, J., Lu, Z., Jiang, J. \& Niu, Y., Preparation and properties of ultralightweight EPS concrete based on pre-saturated bentonite. Construction and Building Materials, 215, 2019.

[4] Solak, A.M. \& Pereiro-Barceló, J., Cost-optimal analysis of concrete solutions for single-family nZEBs applying an Open BIM Workflow. Presented at SynerCrete'18: Interdisciplinary Approaches for Cement-based Materials and Structural Concrete: Synergizing Expertise and Bridging Scales of Space and Time, 2018.

[5] Jafari, S. \& Mahini, S.S., Lightweight concrete design using gene expression programing. Construction and Building Materials, 139, pp. 93-100, 2017.

[6] Jin, Q. \& Li, V.C., Development of lightweight engineered cementitious composite for durability enhancement of tall concrete wind towers. Cement and Concrete Composites, 96, pp. 87-94, 2019.

[7] Pla, C., Tenza-Abril, A.J., Valdes-Abellan, J. \& Benavente, D., Influence of microstructure on fluid transport and mechanical properties in structural concrete produced with lightweight clay aggregates. Construction and Building Materials, 171, 2018.

[8] Nadesan, M.S. \& Dinakar, P., Mix design and properties of fly ash waste lightweight aggregates in structural lightweight concrete. Case Studies in Construction Materials, 7, 2017.

[9] Fernández-Fanjul, A., Tenza-Abril, A.J. \& Baeza-Brotons, F., A new methodology for determining particle density and absorption of lightweight, normal-weight and heavy weight aggregates in aqueous medium. Construction and Building Materials, 146, pp. 630-643, 2017.

[10] Fernández-Fanjul, A., Tenza-Abril, A.J. \& Baeza-Brotons, F., A new methodology for determining water absorption of lightweight, normal-weight and heavyweight aggregates in a viscous medium. Construction and Building Materials, 165, 2018.

[11] Fernández-Fanjul, A. \& Tenza-Abril, A.J., Méthode Fanjul: Dosage pondéral des bétons légers et lourds. Annales du Bâtiment et des Travaux Publics, 5, pp. 32-50, 2012. 
[12] Kewalramani, M.A. \& Gupta, R., Concrete compressive strength prediction using ultrasonic pulse velocity through artificial neural networks. Automation in Construction, 2006.

[13] Tenza-Abril, A.J., Villacampa, Y., Solak, A.M. \& Baeza-Brotons, F., Prediction and sensitivity analysis of compressive strength in segregated lightweight concrete based on artificial neural network using ultrasonic pulse velocity. Construction and Building Materials, 189, pp. 1173-1183, 2018.

[14] Chung, S.Y., Elrahman, M.A., Stephan, D. \& Kamm, P.H., The influence of different concrete additions on the properties of lightweight concrete evaluated using experimental and numerical approaches. Construction and Building Materials, 189, 2018.

[15] Tenza-Abril, A.J., Villacampa, Y., Baeza-Brotons, F., Navarro-González, J.F. \& Solak, A.M., Numerical model for describing the segregation phenomenon in lightweight concrete using density sections. International Journal of Computational Methods and Experimental Measurements, 6, pp. 726-736, 2017.

[16] Solak, A.M., Tenza-Abril, A.J., Baeza-Brotons, F., Garcia-Vera, V.E. \& Lanzón, M., Experimental procedures for determining the level of segregation of lightweight aggregate concretes. Presented at SynerCrete'18: Interdisciplinary Approaches for Cement-based Materials and Structural Concrete: Synergizing Expertise and Bridging Scales of Space and Time, 2018.

[17] Solak, A.M., El fenómeno de la segregación en hormigones ligeros. Análisis mediante procesamiento de imágenes y estudio ultrasónico. Departamento de Ingeniería Civil, 2017.

[18] Solak, A.M., Tenza-Abril, A.J., Baeza-Brotons, F., García-Vera, V.E. \& Lanzón, M., New insights on the segregation due to manufacture conditions of lightweight aggregate concretes. Presented at SynerCrete'18: Interdisciplinary Approaches for Cement-based Materials and Structural Concrete: Synergizing Expertise and Bridging Scales of Space and Time, 2018.

[19] Solak, A.M., Tenza-Abril, A.J., Saval, J.M. \& García-Vera, V.E., Effects of multiple supplementary cementitious materials on workability and segregation resistance of lightweight aggregate concrete. Sustainability, 2018.

[20] Ting, T.Z.H., Rahman, M.E., Lau, H.H. \& Ting, M.Z.Y., Recent development and perspective of lightweight aggregates based self-compacting concrete. Construction and Building Materials, 201, pp. 763-777, 2019.

[21] Cortes, C. \& Vapnik, V., Support-vector networks. Machine Learning, 1995.

[22] Vapnik, V.N., An overview of statistical learning theory. IEEE Transactions on Neural Networks, 1999.

[23] Gaenssler, P. \& Stute, W., Vapnik-Chervonenkis-theory BT. Seminar on Empirical Processes, eds P. Gaenssler \& W. Stute, Birkhäuser: Basel, pp. 87-109, 1987.

[24] Hariri-Ardebili, M.A. \& Pourkamali-Anaraki, F., Support vector machine based reliability analysis of concrete dams. Soil Dynamics and Earthquake Engineering, 104, 2018.

[25] Liu, J., Yan, K.Z., Zhao, X. \& Hu, Y., Prediction of autogenous shrinkage of concretes by support vector machine. International Journal of Pavement Research and Technology, 2016.

[26] Koo, B., La, S., Cho, N.-W. \& Yu, Y., Using support vector machines to classify building elements for checking the semantic integrity of building information models. Automation in Construction, 98, pp. 183-194, 2019. 
[27] Reuter, U., Sultan, A. \& Reischl, D.S., A comparative study of machine learning approaches for modeling concrete failure surfaces. Advances in Engineering Software, 116, pp. 67-79, 2018.

[28] Sonebi, M., Cevik, A., Grünewald, S. \& Walraven, J., Modelling the fresh properties of self-compacting concrete using support vector machine approach. Construction and Building Materials, 106, pp. 55-64, 2016.

[29] Abd, A.M. \& Abd, S.M., Modelling the strength of lightweight foamed concrete using support vector machine (SVM). Case Studies in Construction Materials, 6, pp. 8-15, 2017.

[30] Bogas, J.A., Gomes, M.G. \& Real, S., Capillary absorption of structural lightweight aggregate concrete. Materials and Structures, 48, pp. 2869-2883, 2015.

[31] Videla, C. \& López, M., Efecto de la resistencia intrínseca del árido ligero en la resistencia a compresión y rigidez del hormigón ligero. Materiales de Construcción, 52, 2002.

[32] Bogas, J.A. \& Gomes, A., Compressive behavior and failure modes of structural lightweight aggregate concrete - Characterization and strength prediction. Materials and Design, 46, pp. 832-841, 2013.

[33] Bogas, J.A., Gomes, M.G. \& Gomes, A., Compressive strength evaluation of structural lightweight concrete by non-destructive ultrasonic pulse velocity method. Ultrasonics, 53, pp. 962-972, 2013.

[34] Youm, K.S., Moon, J., Cho, J.Y. \& Kim, J.J., Experimental study on strength and durability of lightweight aggregate concrete containing silica fume. Construction and Building Materials, 114, 2016.

[35] Choi, Y.W., Kim, Y.J., Shin, H.C. \& Moon, H.Y., An experimental research on the fluidity and mechanical properties of high-strength lightweight self-compacting concrete. Cement and Concrete Research, 36, 2006.

[36] Mo, K.H., Alengaram, U.J. \& Jumaat, M.Z., Experimental investigation on the properties of lightweight concrete containing waste oil palm shell aggregate. Procedia Engineering, 125, 2015.

[37] Nepomuceno, M.C.S. \& Silva, P.D., Experimental evaluation of cement mortars with phase change material incorporated via lightweight expanded clay aggregate. Construction and Building Materials, 63, 2014.

[38] Bogas, J.A., de Brito, J. \& Cabaco, J., Long-term behaviour of concrete produced with recycled lightweight expanded clay aggregate concrete. Construction and Building Materials, 65, pp. 470-479, 2014.

[39] Domagała, L., The effect of lightweight aggregate water absorption on the reduction of water-cement ratio in fresh concrete. Procedia Engineering, 108, pp. 206-213, 2015.

[40] Croce, P., Marsili, F., Klawonn, F., Formichi, P. \& Landi, F., Evaluation of statistical parameters of concrete strength from secondary experimental test data. Construction and Building Materials, 163, pp. 343-359, 2018.

[41] Sojobi, A.O., Aladegboye, O.J. \& Awolusi, T.F., Green interlocking paving units. Construction and Building Materials, 173, pp. 600-614, 2018.

[42] Chang, C., Lin, C. \& Tieleman, T., LIBSVM : A library for support vector machines. ACM Transactions on Intelligent Systems and Technology (TIST), 2008.

[43] James, G., Witten, D., Hastie, T. \& Tibshirani, R., Moving beyond linearity. An Introduction to Statistical Learning, Springer: New York, 2013. 
[44] Ni, H.-G. \& Wang, J.-Z., Prediction of compressive strength of concrete by neural networks. Cement and Concrete Research, 30, pp. 1245-1250, 2000.

[45] Yeh, I.C., Modeling of strength of high-performance concrete using artificial neural networks. Cement and Concrete Research, 28, 1998. 